\title{
TB Mobile: a mobile app for anti-tuberculosis molecules with known targets
}

Sean Ekins ${ }^{1,2^{*}}$, Alex M Clark ${ }^{3}$ and Malabika Sarker ${ }^{4}$

\begin{abstract}
Background: An increasing number of researchers are focused on strategies for developing inhibitors of Mycobacterium tuberculosis (Mtb) as tuberculosis (TB) drugs.

Results: In order to learn from prior work we have collated information on molecules screened versus Mtb and their targets which has been made available in the Collaborative Drug Discovery (CDD) database. This dataset contains published data on target, essentiality, links to PubMed, TBDB, TBCyc (which provides a pathway-based visualization of the entire cellular biochemical network) and human homolog information. The development of mobile cheminformatics apps could lower the barrier to drug discovery and promote collaboration. Therefore we have used this set of over 700 molecules screened versus Mtb and their targets to create a free mobile app (TB Mobile) that displays molecule structures and links to the bioinformatics data. By input of a molecular structures and performing a similarity search within the app we can infer potential targets or search by targets to retrieve compounds known to be active.

Conclusions: TB Mobile may assist researchers as part of their workflow in identifying potential targets for hits generated from phenotypic screening and in prioritizing them for further follow-up. The app is designed to lower the barriers to accessing this information, so that all researchers with an interest in combatting this deadly disease can use it freely to the benefit of their own efforts.
\end{abstract}

Keywords: Collaborative drug discovery tuberculosis database, Drug discovery, Mobile applications, Mycobacterium tuberculosis, Tuberculosis, TB Mobile

\section{Background}

Modern drug discovery must be more time- and costefficient in discovering novel therapeutics. These challenges are felt even more significantly in the search for neglected disease treatments. A prime example is tuberculosis (TB), caused by Mycobacterium tuberculosis (Mtb), which infects approximately one-third of the world's population and results in 1.7-1.8 million deaths annually [1]. New drugs active against $M t b$ are urgently needed to combat a pandemic heavily affected by resistance to available therapies and co-infection with HIV/AIDS [2]. The pipeline for TB therapeutics had not produced a new approved drug in over 40 years $[3,4]$. Only a tiny fraction of TB

\footnotetext{
* Correspondence: ekinssean@yahoo.com

'Collaborative Drug Discovery, 1633 Bayshore Highway, Suite 342,

Burlingame, CA 94010, USA

${ }^{2}$ Collaborations in Chemistry, 5616 Hilltop Needmore Road, Fuquay-Varina, NC 27526, USA

Full list of author information is available at the end of the article
}

targets have been addressed with approved drugs and recent testing has targeted additional proteins but this has yet to result in a drug besides bedaquiline for multidrug resistant TB $[5,6]$. This is a pattern observed for other antibacterial targets reflecting the difficulty of target-based high-throughput screening [7]. In recent years there has been an increase in the efforts around high throughput screening (HTS) for $M t b$, in order to find compounds as therapeutics against TB [8-12] at a cost of millions of dollars, with resultant low single-digit (or less) hit rates $[8,9,13,14]$. Whole cell screening, however does not provide any information on the targets for the hits that result and this therefore entails costly follow up. In many cases such target identification is unable to identify one or more target.

While there have been studies that evaluate the role of particular $M t b$ genes and define their potential as targets for new drugs [15] there have been few efforts to predict targets for hits coming from whole cell screening. Various TB-related databases [16] are available that cover
(C) Chemistry Central

C 2013 Ekins et al.; licensee Chemistry Central Ltd. This is an Open Access article distributed under the terms of the Creative Commons Attribution License (http://creativecommons.org/licenses/by/2.0), which permits unrestricted use, distribution, and reproduction in any medium, provided the original work is properly cited. 
diverse areas of TB research like genomes, pathway maps, phylogenetic trees, active compounds, large-scale screening data, resistance-associated mutations, targets, comparative analysis and gene expression data. Pipelines for bioinformatics processes such as target identification in $\mathrm{TB}$ (e.g. targetTB [17]) have also been suggested. We created a collection of $>700$ molecules with $M t b$ target/s along with published data on the target, essentiality, links to literature (PubMed), genes (tbdb.org), pathways (TBCyc, which provides a pathway-based visualization of the entire cellular biochemical network) and human homolog information [18] collated in the course of a previous study [19]. This dataset was made available in the Collaborative Drug Discovery (CDD) database [18].

As mobile devices such as smartphones and tablet computers have seen rapid uptake in recent years and the associated app stores include a growing number of chemistry software apps [20], making data available as an app may help reach a wider audience. These mobile apps generally perform one or two functions and can be thought of as individually packaged features rather than the relatively heavyweight programs commonly used in desktop computing. However, such apps can use data interchange and be used in the workflow to increase the productivity of chemists $[21,22]$. Mobile apps for chemistry are a nascent area to delivering or "appifying" data and may be disruptive to many currently used paradigms for presenting information and for education [23]. A recent example is the Green Solvents mobile App which took data collected on solvents and delivered it as a free look-up tool to help in solvent selection [24].

The recent collation of molecules screened versus $M t b$ and their targets could help in the task of suggesting potential targets for HTS hits [19]. This data was used to create the TB Mobile app that displays molecule structures and links to the bioinformatics data. By input of a molecule structure and performing a similarity search one can infer potential targets or search by targets to retrieve compounds known to be active. The app also has filters to limit the visible molecules by target name, pathway name, essentiality and human ortholog. We now describe TB Mobile [25,26] and its potential applications.

\section{Methods}

\section{Dataset curation}

The process of dataset curation can be broken down into several steps.

1. Identification of essential in vivo enzymes of $M t b$ involved intensive literature mining and manual curation, to extract all the genes essential for $M t b$ growth in vivo across species [27-31].

2. Homolog information was collated from other studies [28,32].
3. Collection of metabolic pathway information involved using TB database (TBDB) [33,34].

4. Identifying molecules and drugs with known or predicted targets [35] involved searching the CDD databases for manually curated data. The structures and data were exported for combination with the other data.

5. All data were combined with URL links to literature and TBDB $[33,34]$ and deposited in the CDD database [18].

\section{TB Mobile app software development}

The iOS app was build using the Objective-C programming language, with the API provided by Apple for native iOS development, while the Android app was built using Java and the standard Android API. The apps have almost identical functionality, with minor aesthetic differences due to the platform. Both of these apps are linked with MMDSLib, which is available separately for both platforms, and provides the core functionality for a number of cheminformatics apps, such as the Mobile Molecular DataSheet (MMDS) [36].

The TB related information was entered manually, and is bundled as part of the app resources. The TB Mobile app was developed as described above then made available on iTunes [25] as a free app for the iPhone, iPod and iPad platforms. The Android version is available free of charge on Google Play [26].

\section{TB Mobile app software application}

The TB Mobile app uses molecule structures grouped as the primary point of entry. These molecules are listed with the targets. The user can use the swiping gesture to scroll through all the solvents, then tap on a molecule of interest. This opens a box which lists the molecule name, CDD number, and resistance information. A second box lists the target ( $R v$ number), a link to TBDB, homolog information, essentiality information, pathway information and gene links to PubMed. Links out to open in other mobile apps like ChemSpider [37], the Mobile Reagents app [38] and MMDS etc. [39] are also provided.

\section{Similarity searching in TB Mobile app}

Similarity comparisons are done by computing simple typed graph fingerprints (up to 4 atoms in size) and computing the Tanimoto coefficient, which gives an indication of structural similarity. Most similar compounds are listed first (from top left to bottom right) in the app.

\section{Predictions targets for new compounds}

Molecules active against $M t b$ were identified in recent publications from different groups, these included HTS. Proposed targets for some of these molecules were also identified in these publications, in some cases. These 


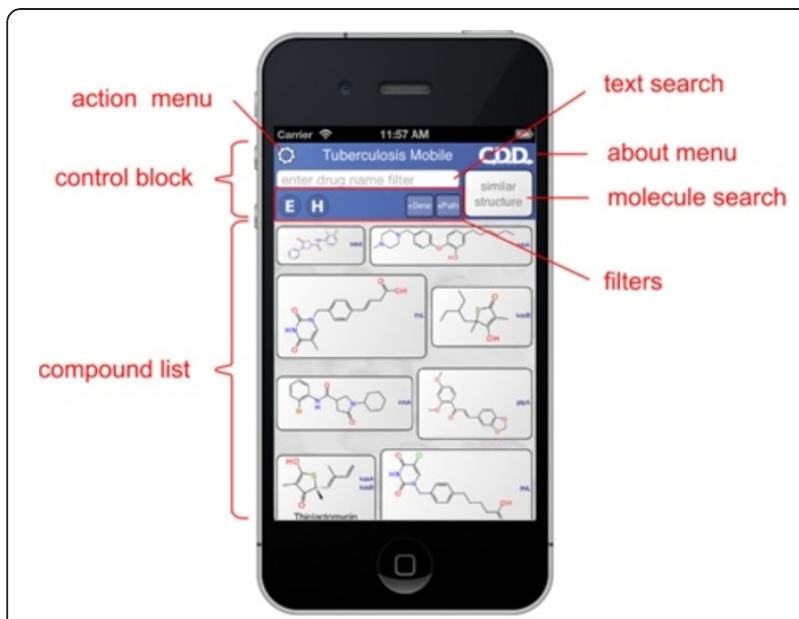

Figure 1 Appearance of the TB Mobile app and identification of functions on an iPhone. The appearance of TB Mobile on an Android Tablet.

molecules were used as a demonstration set to illustrate use of the app. First they were all drawn in the MMDS app and copied into the TB Mobile app (an example of app-to-app communication). Molecules can also be drawn within the TB Mobile app itself. The similarity searching component was used to rank the content in TB Mobile of molecules with known targets. We have used this as an example of inferring potential targets and compared this to the published data for these molecules. It should be noted that such data is far from definitive as these published compounds have not been tested versus all $M t b$ targets and it is possible the same compound may be active against more than one target.

\section{Results}

\section{Dataset curation}

Over 700 molecules with target related information from the literature were curated for use in CDD and TB Mobile.

\section{TB Mobile}

When the app first opens, it takes a moment to organize its data, then displays the main screen (Figure 1). The screen is divided into two blocks: the control block on top, and the compound list underneath. The control block provides means for searching, sorting and filtering the compound list, as well as access to menus, which will be discussed below. The compound list is a vertically scrollable list of compounds, which are indicated primarily by structure, and annotated by name (if available) and target codes. Tapping on any of the compound buttons brings up the corresponding detail view (Figure 2). Most of the detail view is composed of a scrollable list, which shows all of the available information about the compound. In the above example, the structure of isoniazid is shown at the top, along with its name, CDD number, and resistance information. Each of the known target interactions is summarized, which in this case includes InhA. For each target, a variety of information is shown, including human homolog information, whether the target interaction is essential for activity, known biochemical pathways, and a number of links to available reference information. The links can be clicked on, and will launch the mobile browser, providing a significant amount of further detail. The top of the detail view contains several button icons (Figure 3). The select button toggles the bookmark state for the compound. Bookmarked compounds are annotated on the main screen by a folded top right corner (Figure 4). The 'copy' button places a copy of the structure onto the device clipboard, so it can be pasted into other mobile apps, or pasted into the molecular structure search box (described in the next section). The open-in button presents a list of installed apps that are capable of opening molecular structures. If one is selected, then that app is launched and provided with the current structure. The control block provides several ways to modify which compounds are listed, and in what order. Note that if none of these

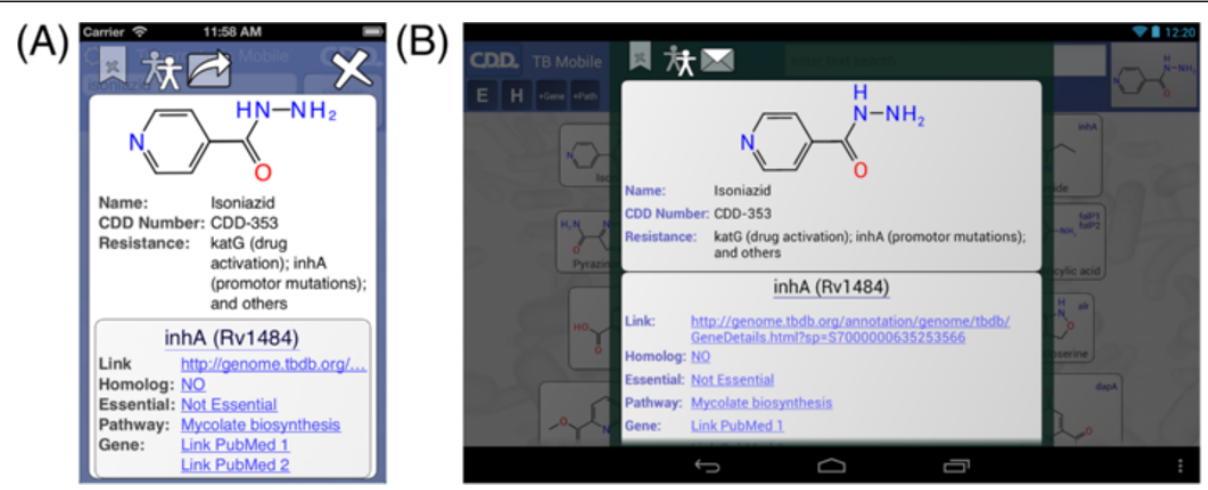

Figure 2 A. Molecule detail and links on the TB Mobile app on an iPhone. B. Molecule detail and links on the TB Mobile app on an Android Tablet. 


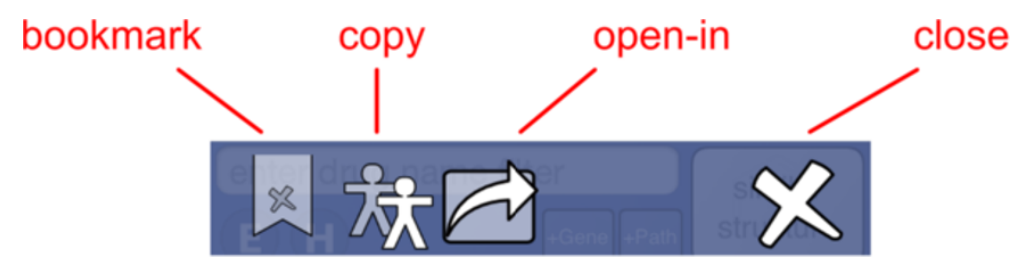

Figure 3 App details in the TB Mobile app on an iPhone.

features are activated, then all of the compounds are displayed, and their order is selected randomly. To restrict the list of compounds to those whose names contain a certain search string, or CDD number, enter text in the search box (Figure 5). Now only clotrimazole and econazole are shown. Many of the compounds currently have no common name, and so will be excluded from this search.

Structural similarity sorting is accomplished by tapping on the structure box at the top right, which allows a chemical structure to be either pasted from the clipboard, or drawn directly using the built in sketcher. The structure sketcher is based on the powerful gesture-

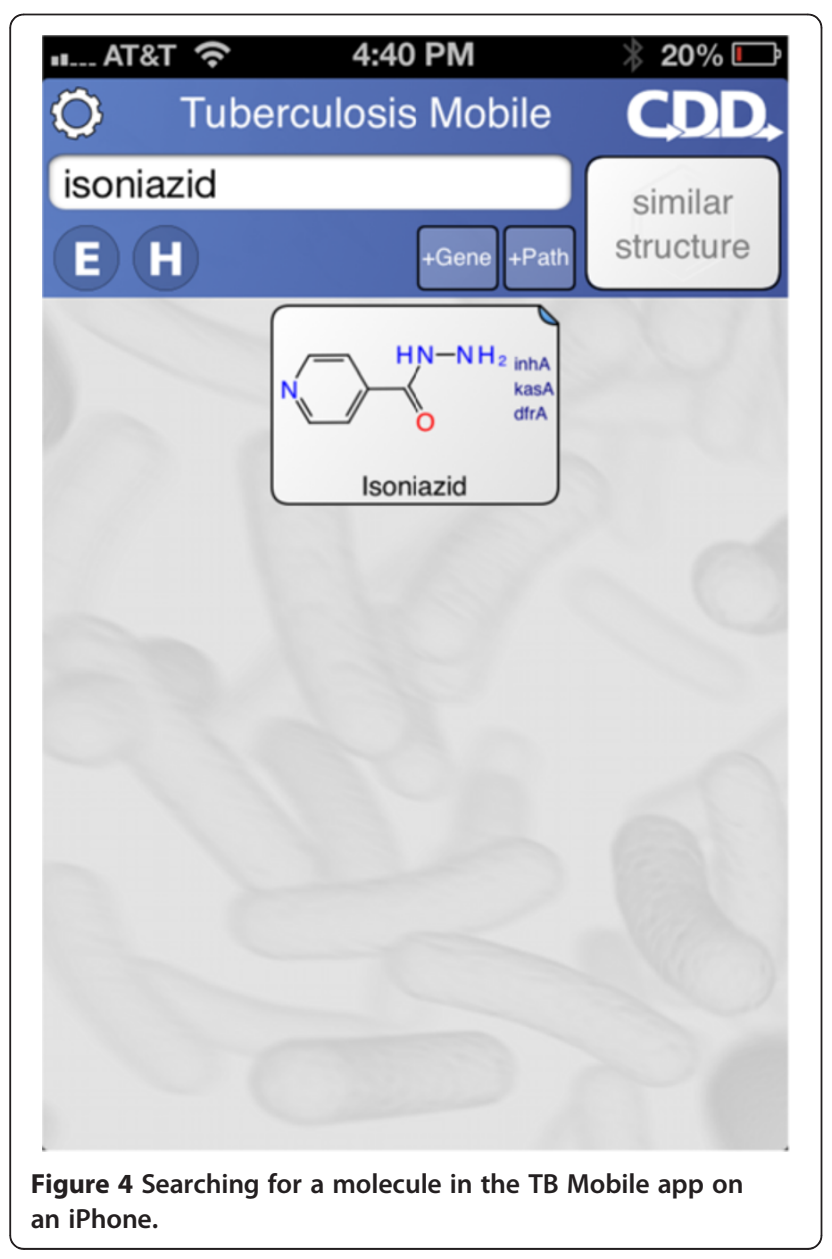

based drawing tools originally developed for the MMDS app, which are designed to make touch-based structure editing fast and effective [40]. For casual users, the app also provides an option to use a less powerful version of the sketcher which is more familiar to users of conventional desktop tools, and so has almost no learning curve. Once the structure is provided, either by editing or pasting, the compound list is sorted according to fingerprint-based similarity to the reference structure (Figure 6). The TB Mobile app can also be opened from other apps that can launch structures (e.g. MolPrime [41]). In this case, the app will perform the structure similarity ordering immediately upon launch.

The control block shows several buttons for filtering (Figure 7). The essential and homolog filters behave similarly: tapping either of these buttons brings up a selection menu with three options (Figure 8). The default state is 'Maybe', i.e. no filtering. Selecting 'Yes' limits the compound list to only those which have at least one target which is considered essential for activity, or has a human homolog, respectively. Selecting 'No' limits the compound list to those which do not have a target satisfying the constraint. The gene filter button brings up a dialog that presents a list of target genes (Figure 9). Each

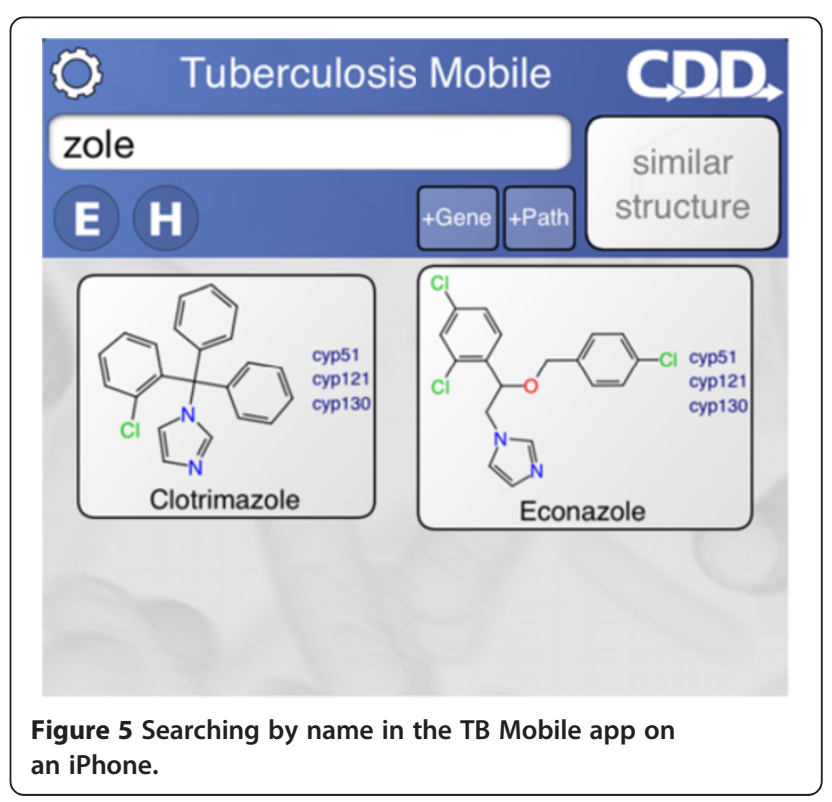




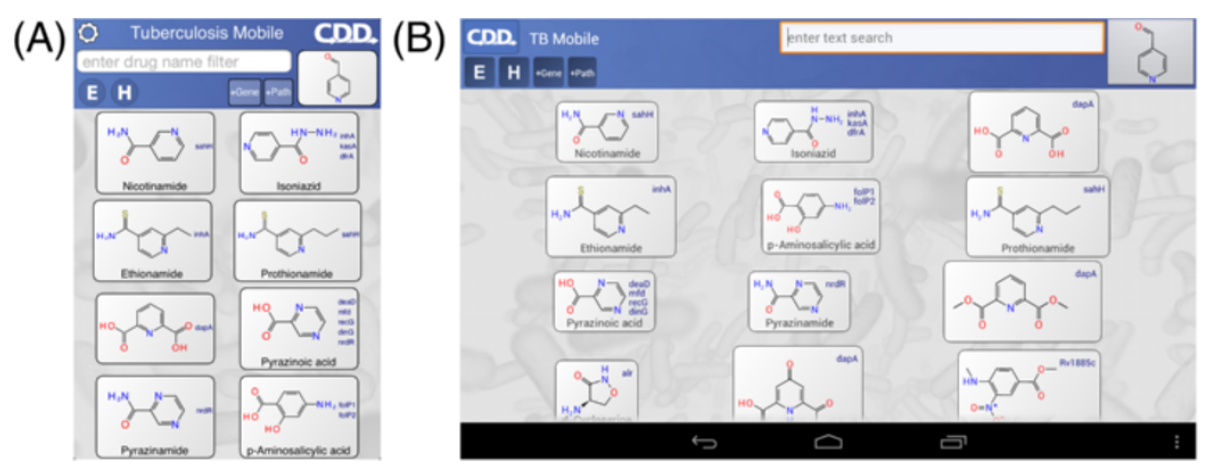

Figure 6 TB Mobile can be used to rank molecules according to their similarity to a reference structure, which can infer potential targets. A. an example in iOS version B. an example in the Android version.

of these genes can be toggled on or off. The compound list will be restricted to those which have activity information about at least one of the selected genes. Similarly, pathways filter button allows known pathways to be selected from an inclusive list (Figure 10). The action menu is activated by pressing the cog icon at the top left (Figure 11). The 'Open in' and 'Send by Email' actions refer to the compounds that are currently displayed onscreen: these can be bundled into a datasheet and handed off to an app that is capable of handling them (e.g. MMDS, SAR Table [42]), or composed as an outgoing email. Outgoing emails include the compounds as an MDL SDfile attachment. These two techniques make it possible to select a subset of the content in TB Mobile and use it with other apps, or make it available to collaborators. There are several menu actions for handling the bookmarked state: bookmarking all currently listed compounds, viewing only bookmarked compounds, and clearing bookmarks.

\section{Predicting targets for new compounds}

In order to illustrate a workflow for using the mobile app we have curated an additional set of 20 molecules published since 2009 that have activity against $M t b$ and were identified by HTS or other methods (Table 1). In some cases purported targets are known and experimentally verified, while in others a mechanism may be known but a target or targets is unknown. For some, there is no known target and the mechanism is unknown. In each case we have used just the input 2D structure of the molecule in TB Mobile to perform a similarity search of the dataset in the app (Additional file 1: Figures S1-S20 illustrate just the first screen of compounds returned in similarity order to the query molecule). The target for the molecule that is ranked most similar is listed for comparison. Some interesting examples stand-out such as pyridomycin, which was recently shown to target InhA (Rv1484) [43], and TB Mobile was able to rank an InhA inhibitor second (Additional file 1: Figure S12). Gliotoxin was found in a recent HTS screen and resistant mutants could not be generated, so the target was not described [9]. However, this molecule was found to be in TB Mobile (Additional file 1: Figure S13) annotated with the target mycothiol-Sconjugate amidase (Mca, Rv1082) and had been discovered previously [44]. In some cases there are very few molecules which represent inhibitors of a particular target. For example there are only two molecules in $\mathrm{TB}$ Mobile that target alanine racemase (Alr, Rv3423c) and two that target dihydrofolate reductase (DfrA, Rv2763c).

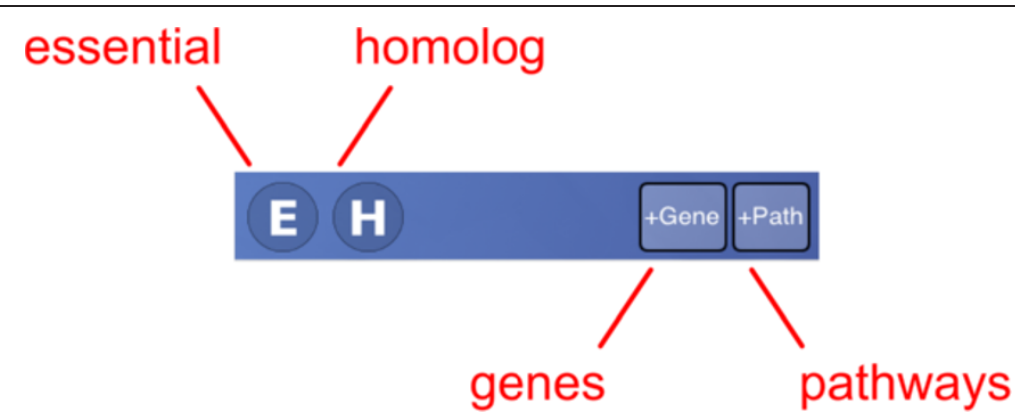

Figure 7 Data can also be filtered by target name, pathway name, essentiality and human ortholog as shown here in the TB Mobile app on an iPhone. 


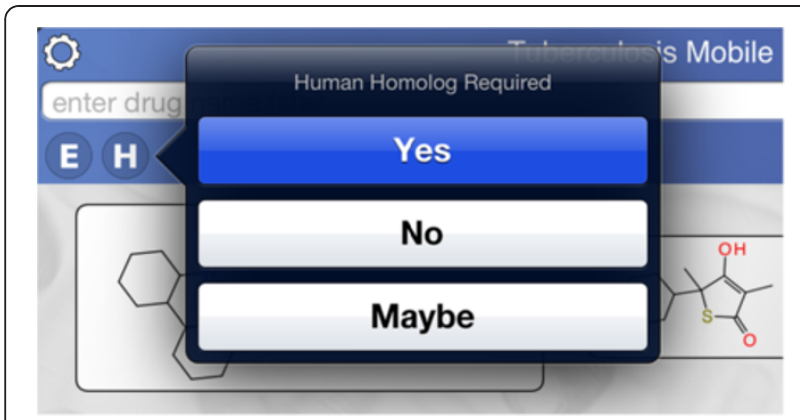

Figure 8 Filtering by homolog in the TB Mobile app on an iPhone.

L2-04 is an example of an inhibitor of Alr identified by HTS [45]. In TB Mobile, a molecule that targets Sadenosylhomocysteine hydrolase (SahH, Rv3248c) is ranked first while the known alr inhibitor, D-cycloserine is ranked $12^{\text {th }}$ out of the set of over 700 compounds (Additional file 1: Figure S1). NC000221 is proposed to target DfrA [46]. Querying TB Mobile with this compound ranked ethambutol as the most similar. Ethambutol targets EmbA (Rv3794), EmbB (Rv3795) and EmbC (Rv3793) and is ranked first while isoniazid (which has many targets including DfrA [47]) was ranked $25^{\text {th }}$ (Additional file 1: Figure S7). This

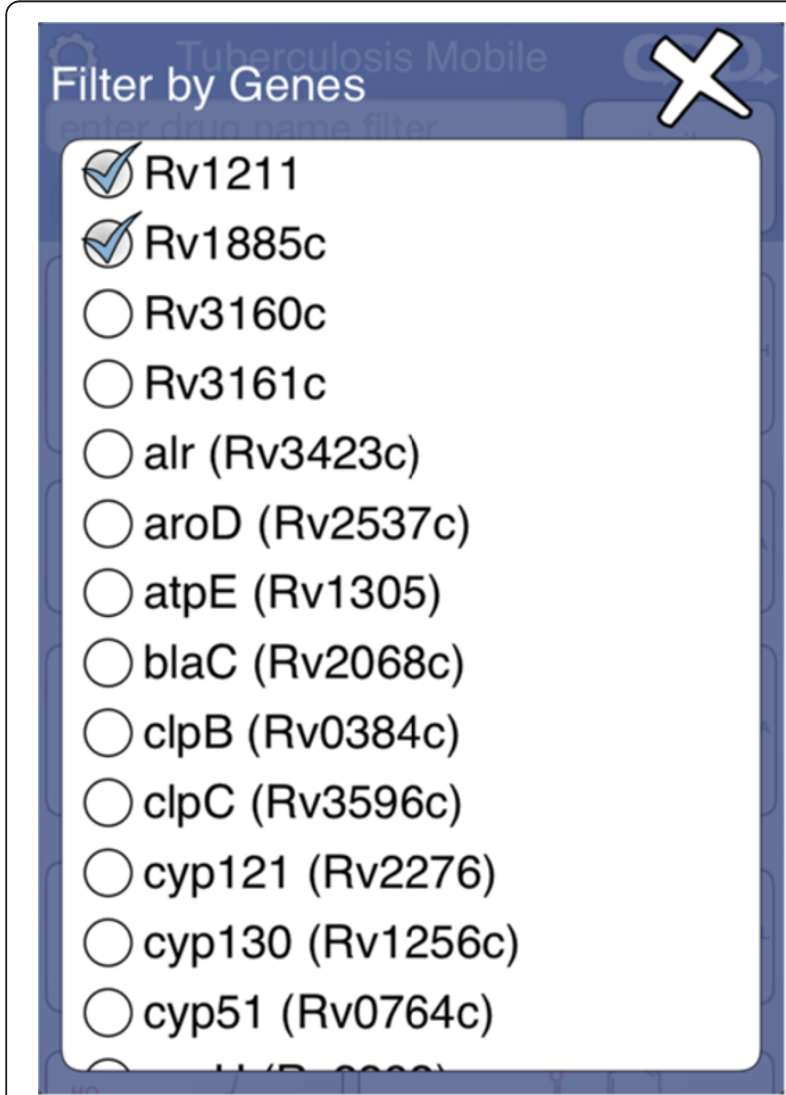

Figure 9 Filtering by genes in the TB Mobile app on an iPhone.

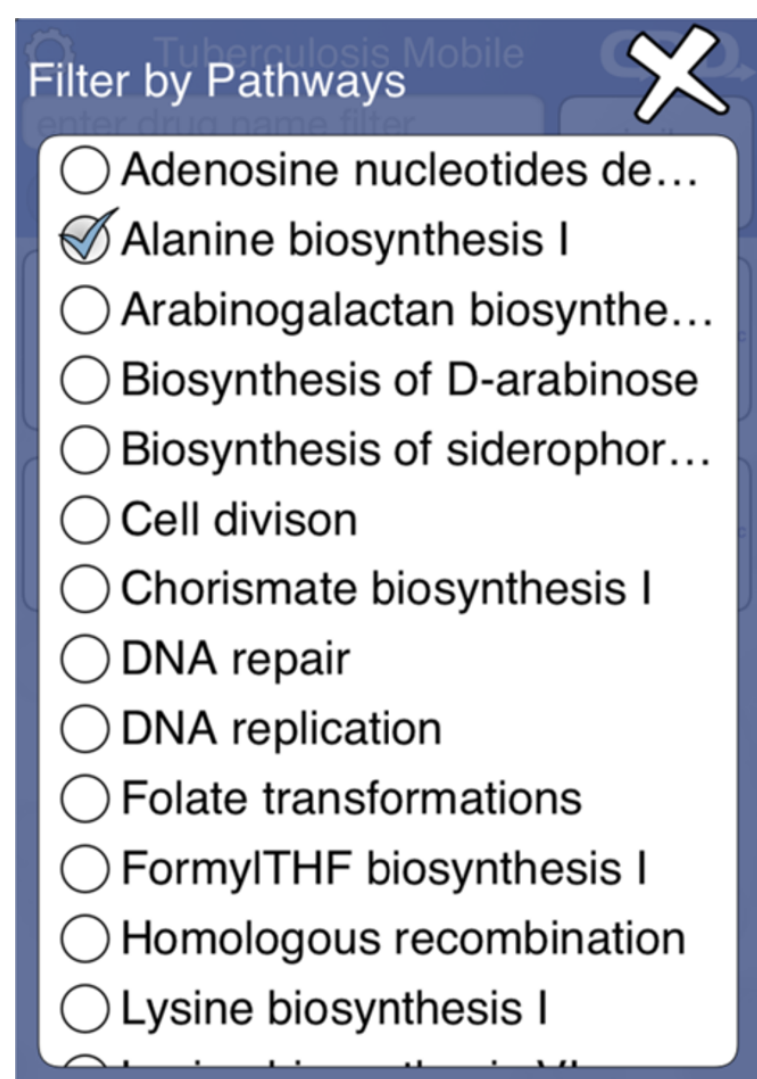

Figure 10 Filtering by pathways in the TB Mobile app on an iPhone.

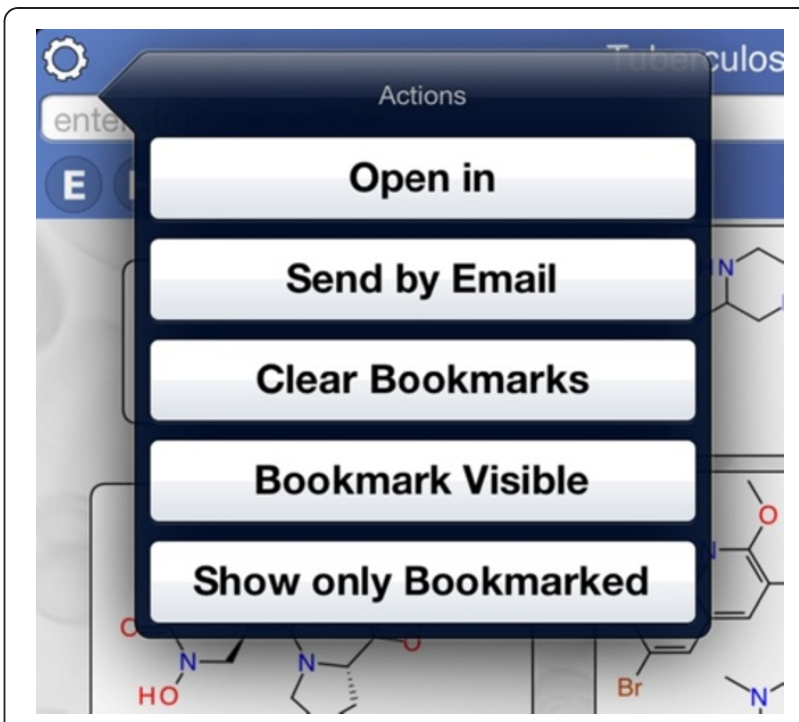

Figure 11 Options for sharing data in the TB Mobile app on an iPhone. 
Table 1 Molecules active against Mtb evaluated in TB Mobile app

\begin{tabular}{lllll}
\hline Molecule & Name & Notes from literature & TB Mobile results most similar & Reference \\
\hline L2-04 & Proposed target is Alr & SahH (D-cycloserine ranked 12 \\
\hline th $)$ & & &
\end{tabular}<smiles>CS(=O)(=O)c1ncc(Cl)c(C(=O)NCc2ccccc2)n1</smiles><smiles>CS(=O)(=O)c1ncc(Cl)c(C(=O)Nc2cccc(Cl)c2)n1</smiles><smiles>COC(=O)c1cccc(C(=O)Oc2ccc(OC(=O)c3cccc(C(=O)OC)n3)c(Cl)c2)n1</smiles><smiles>S=C(Cc1ccccc1)N1CCCCC1</smiles><smiles>CCOc1ccc(CCNC(=O)Cn2sc3nc(C)cc(C)c3c2=O)cc1</smiles><smiles>NC1=NC2C=CC(C(F)(F)F)=CC2C(N)=N1</smiles><smiles>COc1ccc(OCCNC(=O)c2cc([N+](=O)[O-])cc([N+](=O)[O-])c2)cc1</smiles> 


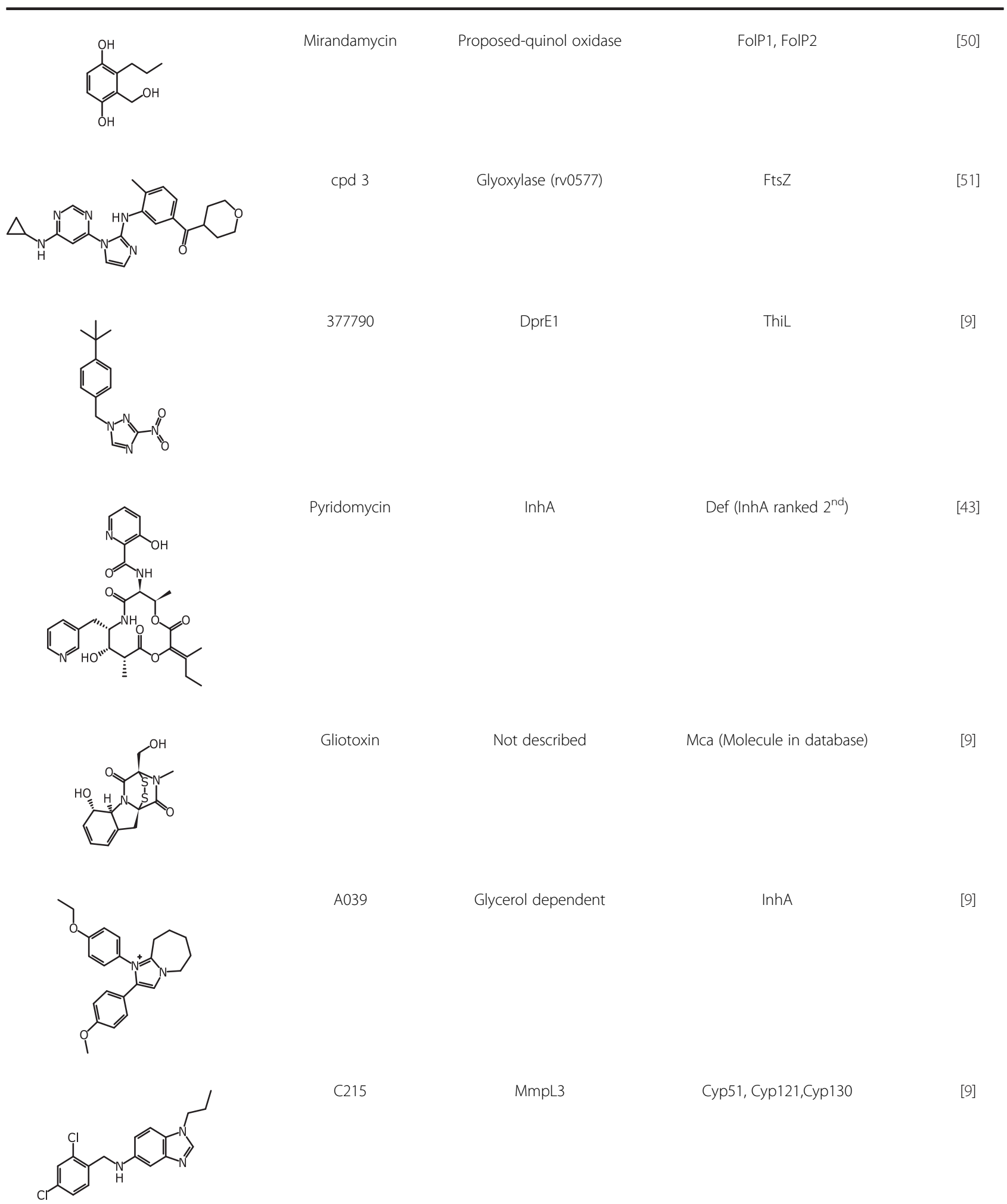




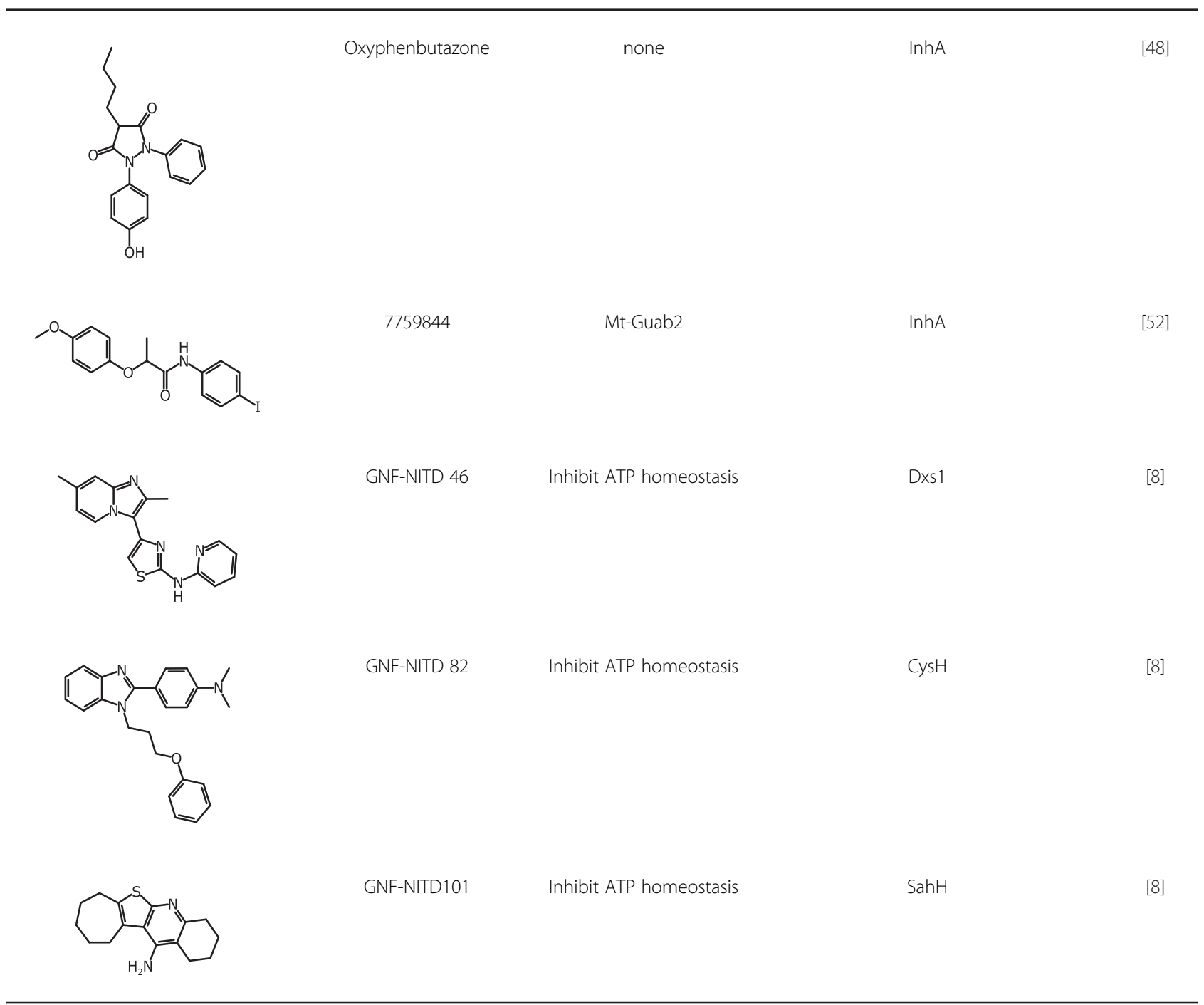

also raises the issue of similarity to compounds like isoniazid that are known to be activated in order to have activity [47]. In other cases there are no representatives of a particular target in TB Mobile e.g. MmpL3 (Rv0206c) [9]. Recently the approved drug oxyphenbutazone (OPB) was identified by HTS as having Mtb activity under aerobic and a 4-stress model of nonreplication [48], although a specific target was not identified. All activity of OPB was shown to be dependent on the acid- and NO dependent conversion of OPB to 4-OH-OPB, which was active on both replicating and non-replicating Mtb. Searching in TB Mobile suggests InhA as a potential target (Additional file 1: Figure S16).

\section{Demonstrating that the app retrieves first line drugs}

Fourteen first line drugs active against $M t b$ from a review [53] were used to demonstrate that the molecules are retrieved first and that similar molecules are in the top positions (Table 2). In all cases the query compound is retrieved first. In many cases the second and third molecules are closely related with identical targets (e.g. amikacin, kanamycin and streptomycin). In others the molecules are structurally similar but known targets are different e.g. ethionamide (InhA), prothionamide (SahH) and nicotinamide (SahH). This may be useful for suggesting potential additional targets of compounds for which it is still unclear. An example here is pyrazinamide which is activated to pyrazinoic acid which may have several targets [54,55] (Table 2).

\section{Discussion}

Within pharmaceutical companies, computational approaches are widely used to aid in drug discovery, but have not been as extensively applied for TB research. We have found several gaps when we look at how computational methods could be used in TB drug discovery including assessing drug-likeness or lead-likeness [56], target deconvolution $[35,57]$, use of sequential virtual and biochemical 
Table 2 First line drugs active against $M t b$ evaluated in TB Mobile app and the top 3 molecules<smiles>CC(C)(C)OC1OC(CO)C(O)C(N)C1OC1OC(CN)C(O)C(O)C1OC1OC(CN)C(O)C(O)C1NC(=O)CCN</smiles><smiles>Nc1ccc(C(=O)O)c(O)c1</smiles>

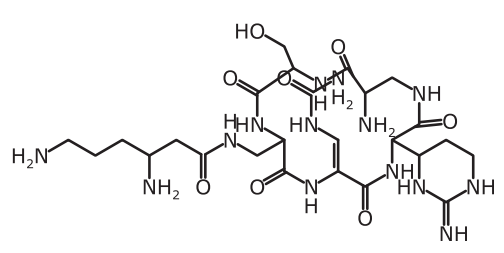<smiles>CC(NC(=O)C(N)CNC(=O)C1CCNC(=N)N1)C(=O)NC(CC(=O)NCC(N)CCCN)C(=O)NC(=O)CNC(N)=O</smiles><smiles>N[C@@H]1CCONC1=O</smiles><smiles>CC[C@H](CO)NCCN[C@H](CC)CO</smiles><smiles>CCc1cc(C(N)=S)ccn1</smiles><smiles>CC1CN(c2c(F)cc3c(=O)c(C(=O)O)cn4c3c2OC2CC24)CCN1</smiles>

Aminosalicylic acid

Capreomycin $1 \mathrm{~A}$

Capreomycin 1A (TlyA)

minosalicylic acid (FolP1, FolP2)
(Rv1885c)

\section{Capreomycin 1B} (RplJ, TlyA)

Kanamycin

(FusA1, FusA2,

Tuf, RplC, InfB)

(FusA1, FusA2,<smiles>C1CCCCC1</smiles>

Capreomycin 1B

D-Cycloserine

Ethambutol (EmbA, EmbB, EmbC)

Ethionamide

Ethionamide (InhA)

Prothionamide (SahH)

Nicotinamide $(\mathrm{SahH})$

Nicotinamide (SahH)

Streptomycin

(FusA1, FusA2

Tuf, RplC)
Ethambutol

\section{(RplJ, TlyA)}

D-cycloserine (Alr)

Ethambutol

(EmbA, EmbB, EmbC)

(DapA)

(DapA)

D-cycloserine (Alr) 
Table 2 First line drugs active against $M t b$ evaluated in TB Mobile app and the top 3 molecules (Continued)

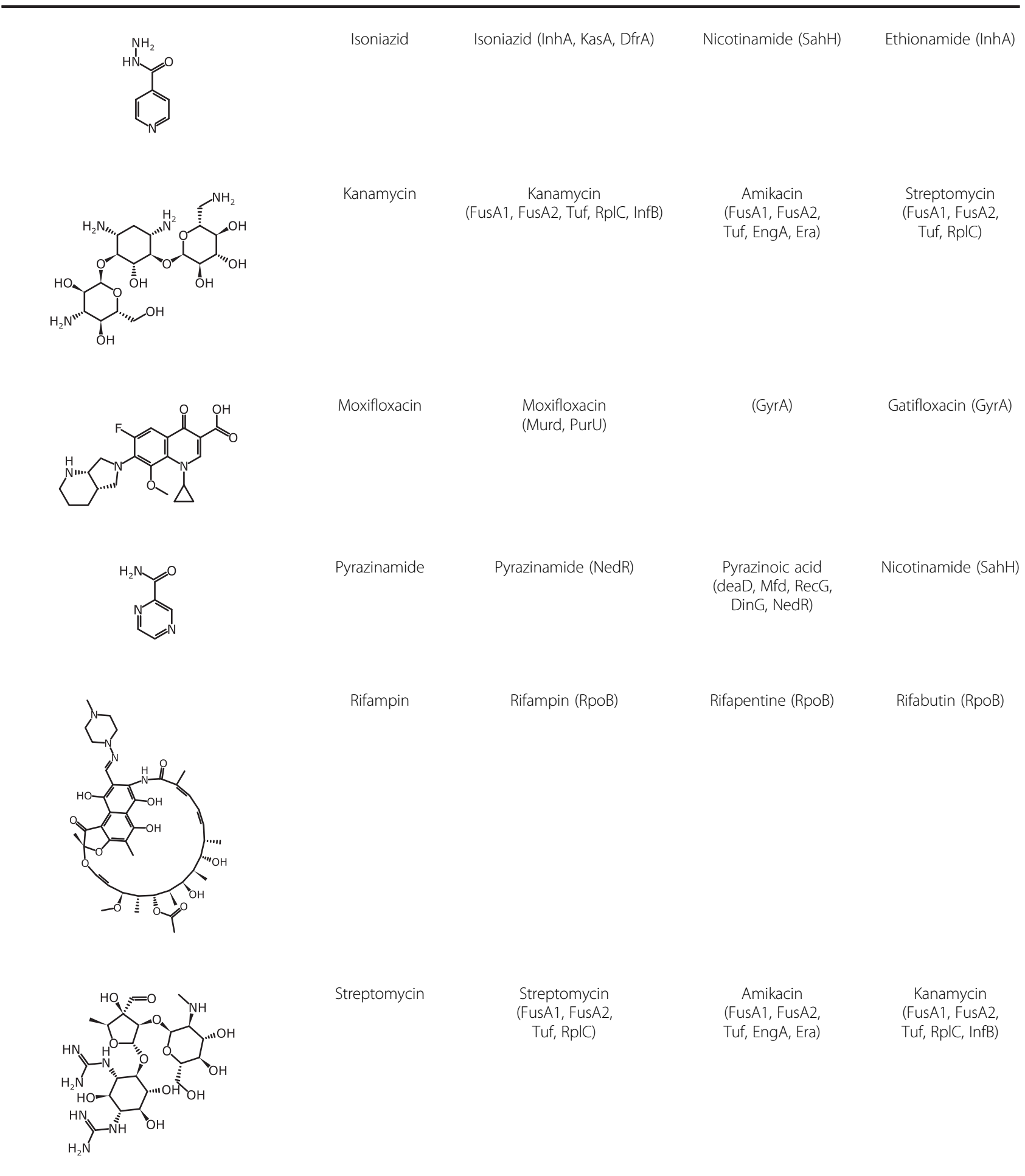


screening and in silico absorption, distribution, metabolism, excretion and toxicity (ADME/Tox) predictions [16]. In the current study we address the target deconvolution issue and methods to assist in prioritization of $M t b$ hits.

In developing mobile apps for cheminformatics we have assumed that many scientists now have a smartphone and/or tablet computer, and that a large majority of these are iOS- or Android-based. Our research aims to deliver cheminformatics solutions via mobile apps as they are easier to use when in the laboratory or in locations without a desktop computer. The TB Mobile app is an example of a reference tool which stores its data locally on the device, so its primary functionality is available even when there is no network connection. While e-lab notebooks are generally used in the office, in contrast a mobile phone will be in the scientists pocket at all times and apps can be used anywhere, anytime and are generally intuitive. Early mobile cheminformatics apps concentrated on solving foundational technical problems like providing a fully functional sketcher on a small, underpowered touchscreen device, and making available computational services [20,21]. TB Mobile is representative of a follow up category which builds on the technical success of the core functionality to provide a very specific product that is highly tuned to the needs of a small but high impact demographic, namely scientists working toward cures for a neglected disease.

We have illustrated a workflow in which compounds derived from Mtb HTS or other screening could be input into TB Mobile to perform a similarity search. This enables the user to see if the compound had been previously identified by others (like gliotoxin, Table 1) and also what the most similar molecules are and their known targets (Table 1, Table 2). This could help with potential follow-up and experimental validation. Of course there are examples of molecules that are active in vitro due to the experimental conditions and when tested in in vivo they have no activity [51], which is an experimental artifact that TB Mobile cannot predict. For some molecules there may be many potential targets in $M t b$. Even if a molecule has one published target that does not prevent it from having another potential target, it just might not have been experimentally verified. We are not suggesting TB Mobile is a definitive target prediction tool, it certainly is not as sophisticated as other methods that use Bayesian [35] and other methods [57]. It does however set the stage to consider what is possible with a scientific mobile app. While molecular similarity may not be the most accurate method to predict potential targets, it is fast and interpretable. Future methods may use more predictive machine learning models $[56,58]$ but will require expansion of the training set of molecules with targets. We envisage in future that updating the content of the app with molecules and targets not currently represented e.g. adding molecules that target MmpL3 and others should enhance the utility of TB Mobile as well as balance out the heavy bias towards targets that are over represented and which occur more frequently in the results (e.g. InhA). One could also consider addition of some weighting or scoring that would normalize the similarity search for the frequency of a target in the dataset. To date there are representatives of 68 targets that likely are the most important targets over the past decade. We hope to add compounds that represent inhibitors of newer targets in future updates.

\section{Conclusion}

In summary, TB Mobile is a simple to use app with useful functionality for viewing and manipulating data about compounds with activity against $M t b$, their targets and other related information. The app represents a significant development in the effort to make accessible drug discovery data freely available in a form that is highly useful to scientists in general, not just cheminformatics experts. The mobile app is freely available for iOS (iPhone, iPod, iPad) and Android devices and will be updated regularly.

\section{Additional file}

Additional file 1: The results of the similarity searches for compounds in Table 1 are shown in Additional file 1: Figures S1-S20. The TB Mobile app is freely available from the Apple iTunes AppStore [25] and Google Play [26].

\section{Competing interests}

Sean Ekins is a consultant for Collaborative Drug Discovery Inc. Alex M. Clark is the founder of Molecular Materials Informatics, Inc., and developed all the apps described.

\section{Authors' contributions}

SE came up with the idea for TB Mobile, performed all the validation experiments described and wrote the manuscript. AMC developed TB Mobile and wrote the manuscript. MS curated database links to molecules used in TB Mobile and wrote the manuscript. All authors read and approved the final manuscript.

\section{Acknowledgements}

We gratefully acknowledge David Blondeau (CDD) for his contributions and delivery of the final product. We also thank Dr. Barry Bunin (CDD) and Dr. Carolyn Talcott (SRI) for their comments on this work.

\section{Funding}

The CDD TB has been developed thanks to funding from the Bill and Melinda Gates Foundation (Grant\#49852 "Collaborative drug discovery for TB through a novel database of SAR data optimized to promote data archiving and sharing"). The project described was supported by Award Number 2R42AI088893-02 "Identification of novel therapeutics for tuberculosis combining

cheminformatics, diverse databases and logic based pathway analysis" from the National Institutes of Allergy and Infectious Diseases.

\section{Author details}

${ }^{1}$ Collaborative Drug Discovery, 1633 Bayshore Highway, Suite 342, Burlingame, CA 94010, USA. ${ }^{2}$ Collaborations in Chemistry, 5616 Hilltop Needmore Road, Fuquay-Varina, NC 27526, USA. ${ }^{3}$ Molecular Materials Informatics, 1900 St. Jacques \#302, Montreal, Quebec H3J 2S1, Canada. ${ }^{4}$ SRI International, 333 Ravenswood Avenue, Menlo Park, CA 94025, USA. 
Received: 11 January 2013 Accepted: 26 February 2013

Published: 6 March 2013

\section{References}

1. Lienhardt C, Glaziou P, Uplekar M, Lonnroth K, Getahun H, Raviglione M: Global tuberculosis control: lessons learnt and future prospects. Nat Rev Microbiol 2012, 10:407-416.

2. Nuermberger EL, Spigelman MK, Yew WW: Current development and future prospects in chemotherapy of tuberculosis. Respirology 2010, 15:764-778.

3. Koul A, Arnoult E, Lounis N, Guillemont J, Andries K: The challenge of new drug discovery for tuberculosis. Nature 2011, 469:483-490.

4. Kaneko T, Cooper C, Mdluli K: Challenges and opportunities in developing novel drugs for TB. Future Med Chem 2011, 3:1373-1400.

5. Andries $K$, Verhasselt $P$, Guillemont J, Gohlmann HW, Neefs JM, Winkler H, Van Gestel J, Timmerman P, Zhu M, Lee E, Williams P, de Chaffoy D, Huitric E, Hoffner S, Cambau E, Truffot-Pernot C, Lounis N, Jarlier V: A diarylquinoline drug active on the ATP synthase of Mycobacterium tuberculosis. Science 2005, 307:223-227.

6. Voelker R: MDR-TB has new drug foe after fast-track approval. JAMA 2013, 309:430.

7. Payne DA, Gwynn MN, Holmes DJ, Pompliano DL: Drugs for bad bugs: confronting the challenges of antibacterial discovery. Nat Rev Drug Disc 2007, 6:29-40

8. Mak PA, Rao SP, Ping Tan M, Lin X, Chyba J, Tay J, Ng SH, Tan BH, Cherian J, Duraiswamy J, Bifani P, Lim V, Lee BH, Ling Ma N, Beer D, Thayalan P, Kuhen K, Chatterjee A, Supek F, Glynne R, Zheng J, Boshoff HI, Barry CE 3rd, Dick T, Pethe K, Camacho LR: A high-throughput screen to identify inhibitors of ATP Homeostasis in Non-replicating Mycobacterium tuberculosis. ACS Chem Biol 2012, 7:1190-1197.

9. Stanley SA, Grant SS, Kawate T, Iwase N, Shimizu M, Wivagg C, Silvis M, Kazyanskaya E, Aquadro J, Golas A, Fitzgerald M, Dai H, Zhang L, Hung DT: Identification of Novel Inhibitors of M. tuberculosis Growth Using Whole Cell Based High-Throughput Screening. ACS Chem Biol 2012, 7:1377-1384.

10. Maddry JA, Ananthan S, Goldman RC, Hobrath JV, Kwong CD, Maddox C, Rasmussen L, Reynolds RC, Secrist JA 3rd, Sosa MI, White EL, Zhang W: Antituberculosis activity of the molecular libraries screening center network library. Tuberculosis (Edinb) 2009, 89:354-363.

11. Ananthan S, Faaleolea ER, Goldman RC, Hobrath JV, Kwong CD, Laughon BE, Maddry JA, Mehta A, Rasmussen L, Reynolds RC, Secrist JA 3rd, Shindo N, Showe DN, Sosa MI, Suling WJ, White EL: High-throughput screening for inhibitors of Mycobacterium tuberculosis H37Rv. Tuberculosis (Edinb) 2009, 89:334-353.

12. Reynolds RC, Ananthan S, Faaleolea E, Hobrath JV, Kwong CD, Maddox C, Rasmussen L, Sosa MI, Thammasuvimol E, White EL, Zhang W, Secrist JA 3rd: High throughput screening of a library based on kinase inhibitor scaffolds against Mycobacterium tuberculosis H37Rv. Tuberculosis (Edinb) 2012, 92:72-83.

13. Macarron R, Banks MN, Bojanic D, Burns DJ, Cirovic DA, Garyantes T, Green DV, Hertzberg RP, Janzen WP, Paslay JW, Schopfer U, Sittampalam GS: Impact of high-throughput screening in biomedical research. Nat Rev Drug Discov 2011, 10:188-195.

14. Magnet S, Hartkoorn RC, Szekely R, Pato J, Triccas JA, Schneider P, SzantaiKis C, Orfi L, Chambon M, Banfi D, Bueno M, Turcatti G, Keri G, Cole ST: Leads for antitubercular compounds from kinase inhibitor library screens. Tuberculosis (Edinb) 2010, 90:354-360.

15. McAdam RA, Quan S, Smith DA, Bardarov S, Betts JC, Cook FC, Hooker EU, Lewis AP, Woollard P, Everett MJ, Lukey PT, Bancroft GJ, Jacobs JWR Jr, Duncan K: Characterization of a Mycobacterium tuberculosis H37Rv transposon library reveals insertions in 351 ORFs and mutants with altered virulence. Microbiology 2002, 148:2975-2986.

16. Ekins S, Freundlich JS, Choi I, Sarker M, Talcott C: Computational databases, pathway and cheminformatics tools for tuberculosis drug discovery. Trends Microbiol 2011, 19:65-74.

17. Raman K, Yeturu K, Chandra N: targetTB: a target identification pipeline for Mycobacterium tuberculosis through an interactome, reactome and genome-scale structural analysis. BMC Syst Biol 2008, 2:109.

18. Hohman M, Gregory K, Chibale K, Smith PJ, Ekins S, Bunin B: Novel webbased tools combining chemistry informatics, biology and social networks for drug discovery. Drug Disc Today 2009, 14:261-270.
19. Sarker M, Talcott C, Madrid P, Chopra S, Bunin BA, Lamichhane G, Freundlich JS, Ekins S: Combining cheminformatics methods and pathway analysis to identify molecules with whole-cell activity against Mycobacterium tuberculosis. Pharm Res 2012, 29:2115-2127.

20. Williams AJ, Ekins S, Clark AM, Jack JJ, Apodaca RL: Mobile apps for chemistry in the world of drug discovery. Drug Disc Today 2011, 16:928-939.

21. Clark AM, Ekins S, Williams AJ: Redefining cheminformatics with intuitive collaborative mobile apps. Molecular Informatics 2012, 31:569-584.

22. Clark AM, Williams AJ, Ekins S: Cheminformatics workflows using mobile apps. Chem-Bio Informatics J 2012. In press.

23. Williams AJ, Pence HE: Smart phones, a powerful tool in the chemistry classroom. J Chem Educ 2011, 88:683-686.

24. Ekins S, Clark AM, Williams AJ: Incorporating green chemistry concepts into mobile chemistry applications and their potential uses. ACS Sustain Chem Eng 2013, 1:8-13.

25. TB Mobile (iOS): [https://itunes.apple.com/us/app/tb-mobile/id567461644?mt=8].

26. TB Mobile (Android): [http://play.google.com/store/apps/details?id=com. mmi.android.tbmobile].

27. Sassetti CM, Boyd DH, Rubin EJ: Genes required for mycobacterial growth defined by high density mutagenesis. Mol Microbiol 2003, 48:77-84.

28. Sassetti CM, Rubin EJ: Genetic requirements for mycobacterial survival during infection. Proc Natl Acad Sci U S A 2003, 100:12989-12994.

29. Lamichhane G, Tyagi S, Bishai WR: Designer arrays for defined mutant analysis to detect genes essential for survival of Mycobacterium tuberculosis in mouse lungs. Infect Immun 2005, 73:2533-2540.

30. Jain SK, Hernandez-Abanto SM, Cheng QJ, Singh P, Ly LH, Klinkenberg LG, Morrison NE, Converse PJ, Nuermberger E, Grosset J, McMurray DN, Karakousis PC, Lamichhane G, Bishai WR: Accelerated detection of Mycobacterium tuberculosis genes essential for bacterial survival in guinea pigs, compared with mice. J Infect Dis 2007, 195:1634-1642.

31. Dutta NK, Mehra S, Didier PJ, Roy CJ, Doyle LA, Alvarez X, Ratterree M, Be NA, Lamichhane G, Jain SK, Lacey MR, Lackner AA, Kaushal D: Genetic requirements for the survival of tubercle bacilli in primates. $J$ Infect Dis 2010, 201:1743-1752.

32. Anishetty S, Pulimi M, Pennathur G: Potential drug targets in Mycobacterium tuberculosis through metabolic pathway analysis. Comput Biol Chem 2005, 29:368-378.

33. Reddy TB, Riley R, Wymore F, Montgomery P, DeCaprio D, Engels R, Gellesch M, Hubble J, Jen D, Jin H, Koehrsen M, Larson L, Mao M, Nitzberg M, Sisk P, Stolte C, Weiner B, White J, Zachariah ZK, Sherlock G, Galagan JE, Ball CA, Schoolnik GK: TB database: an integrated platform for tuberculosis research. Nucleic Acids Res 2009, 37:D499-D508.

34. Galagan JE, Sisk P, Stolte C, Weiner B, Koehrsen M, Wymore F, Reddy TB, Zucker JD, Engels R, Gellesch M, Hubble J, Jin H, Larson L, Mao M, Nitzberg M, White J, Zachariah ZK, Sherlock G, Ball CA, Schoolnik GK: TB database 2010: overview and update. Tuberculosis (Edinb) 2010, 90:225-235.

35. Prathipati P, Ma NL, Manjunatha UH, Bender A: Fishing the target of antitubercular compounds: in silico target deconvolution model development and validation. J Proteome Res 2009, 8:2788-2798.

36. Molecular Materials Informatics: [http://molmatinf.com/mmdslib.html].

37. ChemSpider: [http://www.chemspider.com].

38. Mobile Reagents: [http://mobilereagents.com/].

39. MMDSLib: [http://molmatinf.com/products.html\#section14].

40. Clark AM: Basic primitives for molecular diagram sketching. J Cheminform 2010, 2:8.

41. MolPrime: [http://itunes.apple.com/us/app/molprime/id437087077?mt=8]

42. SAR Table: [https:/itunes.apple.com/us/app/sar-table/id477451419?mt=8].

43. Hartkoorn RC, Sala C, Neres J, Pojer F, Magnet S, Mukherjee R, Uplekar S, Boy-Rottger S, Altmann KH, Cole ST: Towards a new tuberculosis drug: pyridomycin-nature's isoniazid. EMBO Mol Med 2012, 4:1032-1042.

44. Nicholas GM, Eckman LL, Newton GL, Fahey RC, Ray S, Bewley CA: Inhibition and kinetics of mycobacterium tuberculosis and mycobacterium smegmatis mycothiol-S-conjugate amidase by natural product inhibitors. Bioorg Med Chem 2003, 11:601-608.

45. Anthony KG, Strych U, Yeung KR, Shoen CS, Perez O, Krause KL, Cynamon $\mathrm{MH}$, Aristoff PA, Koski RA: New classes of alanine racemase inhibitors identified by high-throughput screening show antimicrobial activity against Mycobacterium tuberculosis. PLoS One 2011, 6:e20374.

46. Kumar A, Zhang M, Zhu L, Liao RP, Mutai C, Hafsat S, Sherman DR, Wang MW: High-throughput screening and sensitized bacteria identify an $M$. 
tuberculosis dihydrofolate reductase inhibitor with whole cell activity. PLoS One 2012, 7:e39961.

47. Argyrou A, Jin L, Siconilfi-Baez L, Angeletti RH, Blanchard JS: Proteome-wide profiling of isoniazid targets in Mycobacterium tuberculosis. Biochemistry 2006, 45:13947-13953.

48. Gold B, Pingle M, Brickner SJ, Shah N, Roberts J, Rundell M, Bracken WC, Warrier T, Somersan S, Venugopal A, Darby C, Jiang X, Warren JD, Fernandez J, Ouerfelli O, Nuermberger EL, Cunningham-Bussel A, Rath P, Chidawanyika T, Deng H, Realubit R, Glickman JF, Nathan CF: Nonsteroidal antiinflammatory drug sensitizes Mycobacterium tuberculosis to endogenous and exogenous antimicrobials. Proc Natl Acad Sci U S A 2012, 109:16004-16011.

49. Christophe T, Jackson M, Jeon HK, Fenistein D, Contreras-Dominguez M, Kim J, Genovesio A, Carralot JP, Ewann F, Kim EH, Lee SY, Kang S, Seo MJ, Park EJ, Skovierova H, Pham H, Riccardi G, Nam JY, Marsollier L, Kempf M, Joly-Guillou ML, Oh T, Shin WK, No Z, Nehrbass U, Brosch R, Cole ST, Brodin $P$ : High content screening identifies decaprenyl-phosphoribose 2 epimerase as a target for intracellular antimycobacterial inhibitors. PLoS Pathog 2009, 5:e1000645.

50. Ymele-Leki P, Cao S, Sharp J, Lambert KG, McAdam AJ, Husson RN, Tamayo G, Clardy J, Watnick PI: A high-throughput screen identifies a new natural product with broad-spectrum antibacterial activity. PLoS One 2012, 7:e31307.

51. Pethe K, Sequeira PC, Agarwalla S, Rhee K, Kuhen K, Phong WY, Patel V, Beer D, Walker JR, Duraiswamy J, Jiricek J, Keller TH, Chatterjee A, Tan MP, Ujjini M, Rao SP, Camacho L, Bifani P, Mak PA, Ma I, Barnes SW, Chen Z, Plouffe D, Thayalan P, Ng SH, Au M, Lee BH, Tan BH, Ravindran S, Nanjundappa M, Lin X, Goh A, Lakshminarayana SB, Shoen C, Cynamon M, Kreiswirth B, Dartois V, Peters EC, Glynne R, Brenner S, Dick T: A chemical genetic screen in Mycobacterium tuberculosis identifies carbon-source-dependent growth inhibitors devoid of in vivo efficacy. Nat Commun 2010, 1:57.

52. Usha V, Hobrath JV, Gurcha SS, Reynolds RC, Besra GS: Identification of novel Mt-Guab2 inhibitor series active against M. tuberculosis. PLoS One 2012, 7:e33886.

53. Sacchettini JC, Rubin EJ, Freundlich JS: Drugs versus bugs: in pursuit of the persistent predator Mycobacterium tuberculosis. Nat Rev Microbiol 2008, 6:41-52

54. Zimhony O, Cox JS, Welch JT, Vilcheze C, Jacobs WR Jr: Pyrazinamide inhibits the eukaryotic-like fatty acid synthetase I (FASI) of Mycobacterium tuberculosis. Nat Med 2000, 6:1043-1047.

55. Shi W, Zhang $X$, Jiang X, Yuan H, Lee JS, Barry CE 3rd, Wang H, Zhang W, Zhang Y: Pyrazinamide inhibits trans-translation in Mycobacterium tuberculosis. Science 2011, 333:1630-1632.

56. Ekins S, Bradford J, Dole K, Spektor A, Gregory K, Blondeau D, Hohman M, Bunin B: A collaborative database and computational models for tuberculosis drug discovery. Mol BioSystems 2010, 6:840-851.

57. Wale N, Karypis G: Target fishing for chemical compounds using targetligand activity data and ranking based methods. J Chem Inf Model 2009, 49:2190-2201

58. Ekins S, Kaneko T, Lipinksi CA, Bradford J, Dole K, Spektor A, Gregory K, Blondeau D, Ernst S, Yang J, Goncharoff N, Hohman M, Bunin B: Analysis and hit filtering of a very large library of compounds screened against Mycobacterium tuberculosis. Mol Biosyst 2010, 6:2316-2324.

doi:10.1186/1758-2946-5-13

Cite this article as: Ekins et al:: TB Mobile: a mobile app for anti-

tuberculosis molecules with known targets. Journal of Cheminformatics 2013 5:13.

\section{Publish with ChemistryCentral and every scientist can read your work free of charge \\ "Open access provides opportunities to our colleagues in other parts of the globe, by allowing anyone to view the content free of charge." \\ W. Jeffery Hurst, The Hershey Company. \\ - available free of charge to the entire scientific community \\ - peer reviewed and published immediately upon acceptance \\ - cited in PubMed and archived on PubMed Central \\ - yours - you keep the copyright \\ Submit your manuscript here: \\ http://www.chemistrycentral.com/manuscript/

